\title{
Risk factors for cement leakage and nomogram for predicting the intradiscal cement leakage after the vertebra augmented surgery
}

Tian-yu Zhang ${ }^{1}$, Pei-xun Zhang ${ }^{1,2}$, Feng Xue 1* $^{*}$, Dian-ying Zhang ${ }^{1,2,3}$ and Bao-guo Jiang ${ }^{1,2}$

\begin{abstract}
Background: Vertebral augmentation is the first-line treatment for the osteoporosis vertebral compression fractures. Bone cement leakage is the most common complication of this surgery. This study aims to assess the risk factors for different types of cement leakage and provides a nomogram for predicting the cement intradiscal leakage.

Methods: We retrospectively reviewed 268 patients who underwent vertebral augmentation procedure between January 2015 and March 2019. The cement leakage risk factors were evaluated by univariate analysis. Different types of cement leakage risk factors were identified by the stepwise logistic analysis. We provided a nomogram for predicting the cement intradiscal leakage and used the concordance index to assess the prediction ability.

Results: A total of 295 levels of vertebrae were included, with a leakage rate of 32.5\%. Univariate analysis showed delayed surgery and lower vertebral compression ratio were the independent risk factors of cement leakage. The stepwise logistic analysis revealed percutaneous vertebroplasty was a risk factor in vein cement leakage; delayed surgery, preoperative compression ratio, and upper endplate disruption were in intradiscal cement leakage; age, preoperative fracture severity, and intravertebral vacuum cleft were in perivertebral soft tissue cement leakage; no factor was in spinal canal cement leakage. The nomogram for intradiscal cement leakage had a precise prediction ability with an original concordance index of 0.75 .
\end{abstract}

Conclusions: Delayed surgery and more vertebral compression increase the risk of cement leakage. Different types of cement leakage have different risk factors. We provided a nomogram for precise predicting the intradiscal cement leakage.

Keywords: Cement leakage, Risk factors, Nomogram, Vertebral augmentation, Vertebral compression fracture

\footnotetext{
* Correspondence: drxuefeng@163.com

'Department of Traumatic Orthopaedics, Peking University People's Hospital, No.11 South Avenue, Xi Zhi Men, Xicheng District, Beijing 100044, China

Full list of author information is available at the end of the article
}

(c) The Author(s). 2020 Open Access This article is licensed under a Creative Commons Attribution 4.0 International License, which permits use, sharing, adaptation, distribution and reproduction in any medium or format, as long as you give appropriate credit to the original author(s) and the source, provide a link to the Creative Commons licence, and indicate if changes were made. The images or other third party material in this article are included in the article's Creative Commons licence, unless indicated otherwise in a credit line to the material. If material is not included in the article's Creative Commons licence and your intended use is not permitted by statutory regulation or exceeds the permitted use, you will need to obtain permission directly from the copyright holder. To view a copy of this licence, visit http://creativecommons.org/licenses/by/4.0/ The Creative Commons Public Domain Dedication waiver (http://creativecommons.org/publicdomain/zero/1.0/) applies to the data made available in this article, unless otherwise stated in a credit line to the data. 


\section{Background}

Osteoporosis vertebral compression fractures (OVCFs) are the most common type of osteoporosis fracture. First-line approach for pain relief and kyphosis correction of OVCFs is vertebral augmentation, including percutaneous vertebroplasty (PVP) and percutaneous kyphoplasty (PKP) $[1,2]$. Though the technique of operation has developed, surgical complications still remain great concern.

The cement leakage ranks first among the complications of vertebral augmentation [3], defined as the presence of any extra-vertebral cement. It includes four main types: vein leakage, intradiscal leakage, perivertebral soft tissue leakage, and spinal canal leakage [4]. Though most leakage is asymptomatic, severe outcomes could happen, such as pulmonary emboli $[5,6]$ caused by cement vein leakage and nerve compression caused by spinal canal cement leakage $[7,8]$. These are catastrophic complications. Moreover, the intradiscal leakage increases the risk of adjacent vertebral fractures [9-11] leading to recurrence of pain. Hence, it is vital to find the risk factors for the leakage to instruct us in predicting and preventing it.

The purpose of this study is to evaluate the independent risk factors of different types of cement leakage and provide a nomogram for predicting the intradiscal cement leakage after PKP and PVP.

\section{Methods}

\section{Selection criteria}

This study is a retrospective cohort study. We retrospectively reviewed 507 vertebral compression fracture patients in our medical center between January 2015 and June 2019. The patients need to meet the inclusion criteria as follows: (1) symptomatic OVCFs; (2) treated with unilateral PVP or PKP; (3) magnetic resonance imaging (MRI) revealed the fresh vertebral fracture related to the back pain. The exclusion criteria were as follows: (1) fracture caused by tumor or infection; (2) patients underwent the vertebral fusion surgery at the augmented level; (3) patients with radiating pain. Finally, 268 patients with 295 levels of vertebrae were included.

\section{Factors measurement}

According to the preoperative X-ray, cortical disruption was divided into four types: the disruption of the upper endplate, the lower endplate, the anterior wall, and the posterior wall. The time before surgery was divided into the early stage for less than 30 days and delayed stage for more than 30 days between trauma and surgery. Preoperative fracture severity was classified into grade 1 : mild $(<25 \%$ collapse) and grade 2 : moderate to severe (>25\%) [12]. Preoperative MRI was used to identify preoperative intravertebral vacuum cleft (IVC). The

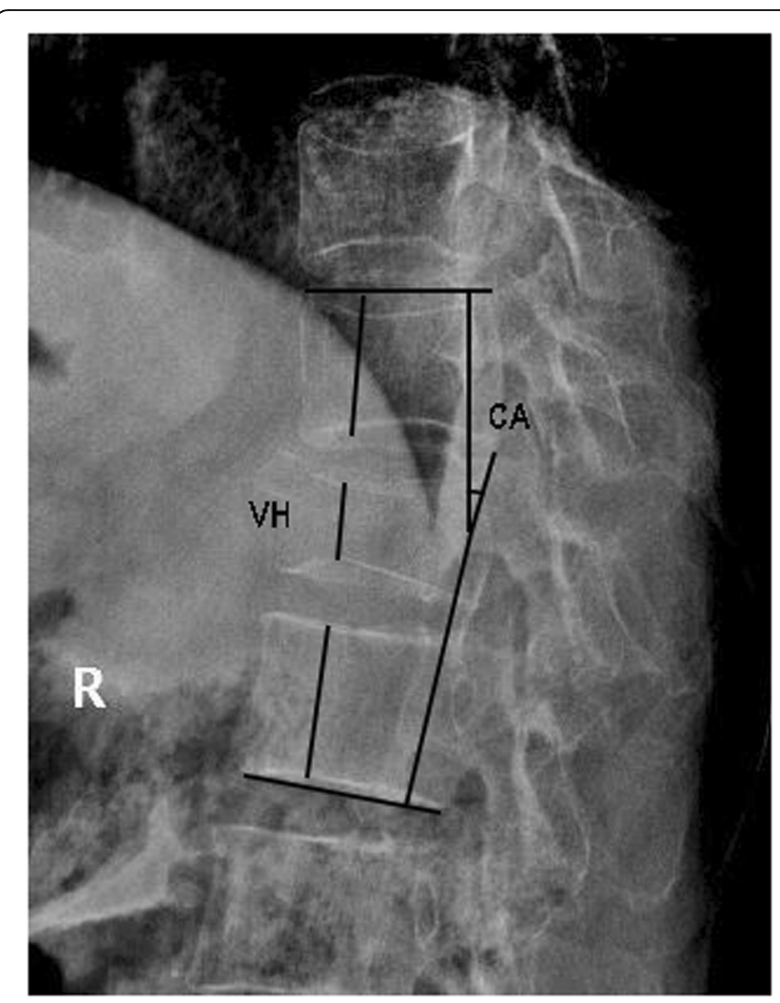

Fig. 1 The measurement method of the vertebral height $(\mathrm{VH})$ and the Cobb angle (CA)

performance of the IVC was an area of hypointensity on T1-weighted, hyper or hypointensity signal on T2weighted and T2-fat suppression images with "double line" on the margin of the area [13].

The radiologic parameters were vertebral height $(\mathrm{VH})$ and Cobb angle (CA) measured from the X-ray. We chose the vertebra's maximal compression point for $\mathrm{VH}$ measurement and the corresponding point of upper and lower vertebra [14] (Fig. 1). The CA was measured between the superior endplate of the vertebra above the augmented vertebra and the lower endplate of the vertebra below the augmented vertebra [15] (Fig. 1). The vertebral compression ratio was the ratio of preoperative fractured vertebral $\mathrm{VH}$ to the average of upper and lower VH.

We assessed the risk factors that potentially influenced the cement leakage, including the age, gender, time before surgery, preoperative fracture severity, preoperative $\mathrm{CA}$, preoperative vertebral compression ratio, preoperative IVC, cement volume, surgery method (PKP or PVP), upper endplate disruption, lower endplate disruption, posterior wall disruption, and anterior wall disruption.

\section{Surgical procedures}

All surgeries were performed by a group of experienced surgeons. Patient lay in a prone position with local 
anesthesia. Vertebral augmentation approach was unipedicle. After the puncture needle arrived at the anterior $1 / 3$ of the vertebra, "toothpaste-like" cement was injected into it. A balloon was inflated to restore the vertebral height in the PKP before the cement injection. All operations were performed under the guidance of the Carm machine. The patient was asked to have bed rest for at least $5 \mathrm{~h}$ after the surgery and wear the brace for 1 month.

\section{Outcome measurement}

As the postoperative CT was not necessary for the vertebra augmented [16], we chose the X-ray for assessing the cement leakage. According to the previous studies [3, 17], we classified the cement leakage patterns into: (1) the vein leakage, (2) the perivertebral soft tissue leakage, (3) the spinal canal leakage, (4) the intradiscal leakage (Fig. 2).

\section{Statistical analysis}

Univariate and multivariate analysis was performed using SPSS Ver. 22.0 for Windows (IBM Corp. NY, USA). Univariate analysis was carried out with Chi square tests for dichotomous factors and univariate logistic regression for continuous factors. $P$ value $<0.05$ was considered as significant difference. Stepwise binary logistic analysis was performed for finding the risk factors of different types cement leakage. 0.05 was the cutoff $\mathrm{P}$ value for the statistical difference. The nomogram and the concordance index were provided by $\mathrm{R}$ statistical software ( $\mathrm{R}$ 3.6.3, R Foundation for Statistical Computing, Vienna, Austria).

\section{Results}

We retrospectively reviewed 268 patients (56 males and 212 females) from January 2015 to March 2019. A total of 295 levels of vertebrae were included, and the cement leakage rate was $32.5 \%$ (Table 1). 240 (89.6\%) patients received one vertebra augmented, 27 (10.1\%) patients received 2 vertebrae augmented and $1(0.4 \%)$ patient received 3 vertebrae augmented. The most common cement leakage type was intradiscal leakage $(44,14.9 \%)$ followed with perivertebral soft tissue leakage $(35,11.9 \%)$, vein leakage $(22,7.5 \%)$, and spinal canal leakage $(8,2.7 \%)$ (Table 1$)$.

Univariate analysis showed that delayed surgery $(\mathrm{OR}=$ $1.85,95 \% \mathrm{CI}=0.76-2.12, P=0.033)$ was the risk factor of cement leakage and univariate logistic analysis showed

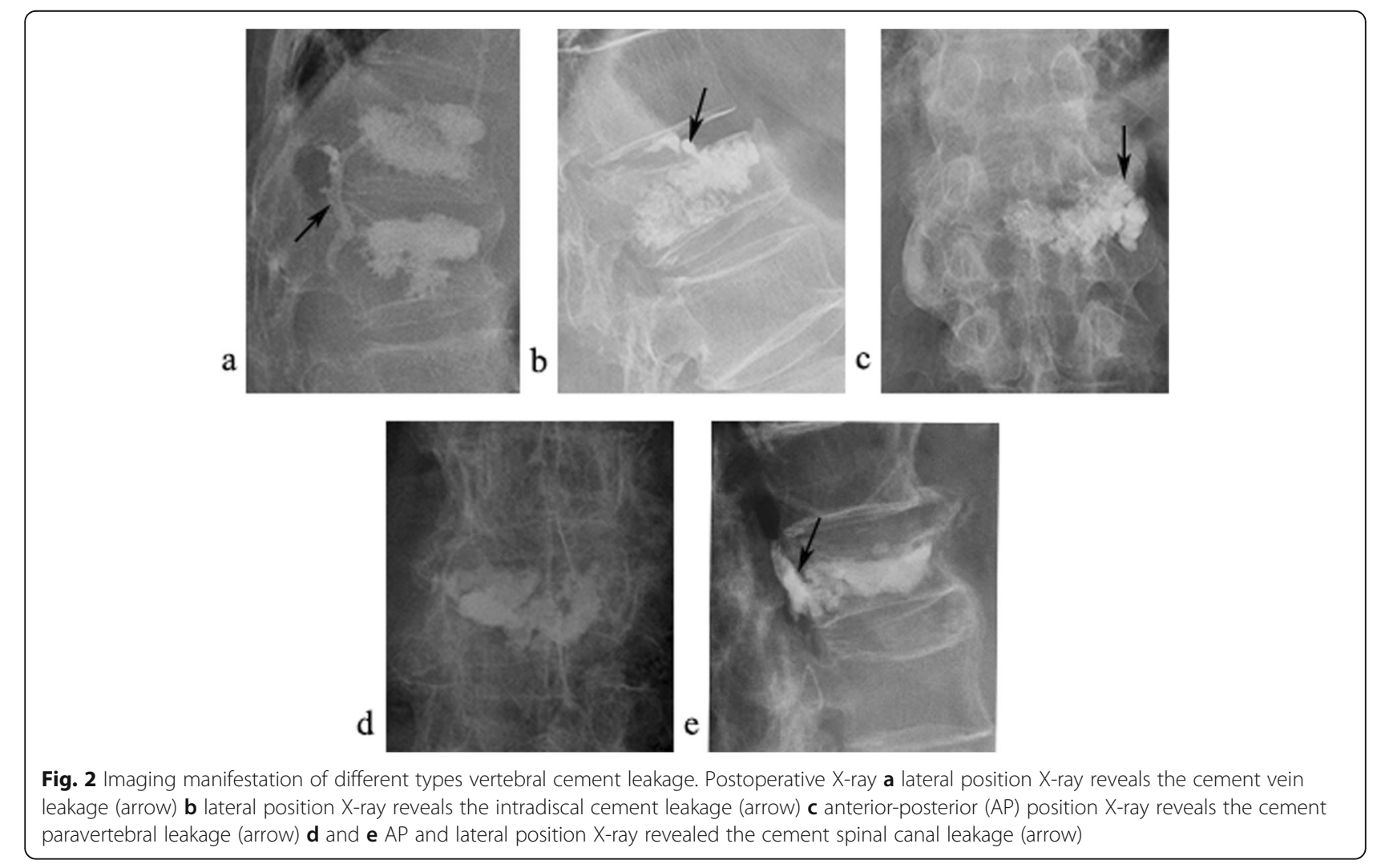


Table 1 Characteristics of patients

\begin{tabular}{|c|c|}
\hline Number of patients, n (\%) & 268 \\
\hline Male & $56(20.8)$ \\
\hline Female & $212(79.2)$ \\
\hline Mean age, $y$ & 74.1 \\
\hline Levels of vertebrae, $\mathrm{n}$ & 295 \\
\hline \multicolumn{2}{|l|}{ Cortical disruption, n (\%) } \\
\hline Upper endplate & $189(64.1)$ \\
\hline Lower endplate & $30(10.2)$ \\
\hline Anterior wall & 79 (26.8) \\
\hline Posterior wall & $7(2.4)$ \\
\hline \multicolumn{2}{|l|}{$\begin{array}{l}\text { Number of treated vertebrae } \\
\text { Per session, } n(\%)\end{array}$} \\
\hline 1 & $240(89.6)$ \\
\hline 2 & $27(10.1)$ \\
\hline 3 & $1(0.4)$ \\
\hline \multicolumn{2}{|l|}{ Surgery method, n (\%) } \\
\hline PKP & $198(67.1)$ \\
\hline PVP & $97(32.9)$ \\
\hline Preoperative IVC, n (\%) & $68(23.1)$ \\
\hline Total cement leakage, n (\%) & $96(32.5)$ \\
\hline Vein leakage & $22(7.5)$ \\
\hline Intradiscal leakage & $44(14.9)$ \\
\hline Perivertebral soft tissue leakage & 35 (11.9) \\
\hline Spinal canal leakage & $8(2.7)$ \\
\hline
\end{tabular}

PKP percutaneous kyphoplasty, PVP percutaneous vertebroplasty, IVC intravertebral vacuum cleft

that vertebral compression ratio $(\mathrm{OR}=0.23,95 \% \mathrm{CI}=$ $0.65-0.83, P=0.025)$ was the risk factor of cement leakage (Table 2).

All factors potentially influencing the cement leakage, as mentioned in the methods section, were included in the stepwise binary logistic analysis. Stepwise binary logistic analysis revealed that PVP $(\mathrm{OR}=5.52,95 \% \mathrm{CI}=$ 2.05-14.89, $P=0.001)$ was an independent risk factor of vein leakage. Delayed surgery $(\mathrm{OR}=2.74,95 \% \mathrm{CI}=1.35$ 5.59, $P=0.005)$, preoperative vertebral compression ratio $(\mathrm{OR}=0.13,95 \% \mathrm{CI}=0.02-0.84, P=0.032)$, and upper endplate disruption $(\mathrm{OR}=2.74,95 \% \mathrm{CI}=1.14-6.56, P=$ $0.024)$ were risk factors of intradiscal leakage. Age (OR = 1.06, 95\% CI $=1.01-1.12, P=0.011)$, preoperative fracture severity $(\mathrm{OR}=2.82,95 \% \mathrm{CI}=1.20-6.61, P=0.017)$, and preoperative IVC $(\mathrm{OR}=2.88,95 \% \mathrm{CI}=1.33-6.23$, $P=0.007$ ) were risk factors of perivertebral soft tissue leakage. No risk factor was relevant with the spinal canal leakage (Table 3).

We depicted the nomogram according to the independent risk factors in the stepwise binary logistic analysis (Fig. 3). To use the nomogram for predicting the risk of intradiscal cement leakage, we can locate the patients values at each factor axis, acquire the corresponding points and sum them up. Then we can locate the sum on total point axis and draw downward to the risk axis to acquire the probability of intradiscal leakage. Nomogram for intradiscal cement leakage had an original concordance index of 0.75 (Fig. 4).

\section{Discussion}

To the best of our knowledge, we firstly provided a nomogram for predicting the cement intradiscal leakage after the vertebral augmentation identified by the postoperative X-ray. Moreover, we assessed the influence of different cortical disruption types on cement leakage.

The upper endplate disruption was the most common type in the vertebral cortical disruption (64.1\%) and the second was anterior wall disruption (26.8\%). This meets the basic biomechanics rules. When a person falls, the stress is from the top to bottom, and the upper endplate is firstly destroyed. The anterior wall breaks as the stress becomes stronger. Only under huge stress, the lower endplate (10.2\%) and posterior wall (2.4\%) got involved.

We reported a cement leakage rate of $32.5 \%$. In previous studies, the cement leakage rate identified by postoperative X-ray was $58.2 \%$ after PVP [17]. The CT identification cement leakage rate was $76.8-81 \%[3,18,19]$. Though CT was more sensitive than X-ray, X-ray was enough for most leakage detection and performed as a proper radiological tool [16]. CT was needed only when spinal canal leakage or neurological symptoms after vertebral augmentation happens.

Delayed surgery was found to be a risk factor of cement leakage. Theoretically, hematoma absorption and fracture line hardening result in higher intravertebral pressure by the time according to bone healing process, and the cement is more likely to leak to the direction of low pressure. Therefore, the cement is more likely to leak in delayed surgery group. However, Guan [20] reported the contrary result. Ren [21] evaluated the freshness of vertebral fracture identified by preoperative MRI, and found no relationship with the cement leakage. This may cause by the different criterion of time point. More vertebral compression was also the risk factor of cement leakage. The vertebral compression ratio was agreed as a risk factor for cement leakage by numerous studies [18, 19, 22, 23]. The more compression of the vertebra always means the more cortical breakage, which results in cement leakage.

We analyzed different types of cement leakage because of their different sequelae.

Cement vein leakage was mostly asymptomatic. However, cement pulmonary embolism might be catastrophic [5]. PVP was the risk factor for the vein leakage (OR = 5.46) comparing to PKP. The inflated balloon provided a cavity for the cement, which reduced the pressure 
Table 2 Chi-square tests were performed for dichotomous factors of cement leakage and univariate logistic regression analyses were performed for continuous factors of cement leakage

\begin{tabular}{|c|c|c|c|}
\hline Preoperative factors $(\mathrm{n})$ & Cement leakage $(n, \%)$ & OR $(95 \% \mathrm{Cl})$ & $P$ value \\
\hline \multicolumn{4}{|l|}{ Dichotomous factors } \\
\hline Gender & & & 0.653 \\
\hline Male (65) & $23(35.4)$ & 1 & \\
\hline Female (230) & $73(31.7)$ & $0.85(0.48-1.52)$ & \\
\hline Time before surgery & & & $0.033^{*}$ \\
\hline Early stage (218) & $63(28.9)$ & 1 & \\
\hline Delayed stage (77) & $33(42.9)$ & $1.85(1.08-3.16)$ & \\
\hline Preoperative fracture severity & & & 0.104 \\
\hline Grade 1 (132) & $36(27.3)$ & 1 & \\
\hline Grade 2 (163) & $60(36.8)$ & $1.27(0.76-2.12)$ & \\
\hline Preoperative IVC & & & 0.184 \\
\hline No (227) & $69(30.4)$ & 1 & \\
\hline Yes (68) & $27(39.7)$ & $1.51(0.86-2.65)$ & \\
\hline Surgery method & & & 0.428 \\
\hline PKP (198) & $61(30.8)$ & 1 & \\
\hline PVP (97) & $35(36.1)$ & $1.55(0.94-2.56)$ & \\
\hline \multicolumn{4}{|l|}{ Continuous factors } \\
\hline Age (years) & & $1.02(0.99-1.05)$ & 0.144 \\
\hline Preoperative CA & & $1.01(0.99-1.04)$ & 0.398 \\
\hline Preoperative compression ratio (\%) & & $0.23(0.65-0.83)$ & $0.025^{*}$ \\
\hline Cement volume (ml) & & $0.99(0.76-1.28)$ & 0.935 \\
\hline
\end{tabular}

IVC intravertebral vacuum cleft, PKP percutaneous kyphoplasty, PVP percutaneous vertebroplasty, CA Cobb angle ${ }^{*} P<0.05$

Table 3 Results of stepwise logistic analysis for risk factors of four different type leakage patterns

\begin{tabular}{llll}
\hline Leakage patterns and risk factors & OR & $\mathbf{9 5 \% C l}$ & $\boldsymbol{P}$ values \\
\hline $\begin{array}{l}\text { Vein leakage } \\
\quad \text { Surgery method (PVP) }\end{array}$ & 5.52 & $2.05-14.89$ & 0.001 \\
$\begin{array}{l}\text { Intervertebral leakage } \\
\quad \text { Delayed surgery }\end{array}$ & 2.74 & $1.35-5.59$ & 0.005 \\
$\quad \begin{array}{l}\text { Preoperative compression ratio } \\
\quad \text { Upper endplate disruption }\end{array}$ & 0.13 & $0.02-0.84$ & 0.032 \\
$\quad$ Perivertebral soft tissue leakage & & $1.14-6.56$ & 0.024 \\
$\quad$ Age & 1.06 & $1.01-1.12$ & 0.011 \\
$\quad$ Preoperative fracture severity & 2.82 & $1.20-6.61$ & 0.017 \\
$\quad$ Preoperative IVC & 2.88 & $1.33-6.23$ & 0.007 \\
Spinal canal leakage & & & \\
$\quad$ Preoperative CA & 0.93 & $0.85-1.02$ & $0.119^{*}$ \\
\hline
\end{tabular}

IVC intravertebral vacuum cleft, PVP percutaneous vertebroplasty, CA Cobb angle

*P $>0.05$ during injection process [24]. As a consequence, the vein cement leakage could be reduced.

Numerous studies showed that intradiscal cement leakage could increase adjacent vertebral fractures [9-11, 25]. Delayed surgery, vertebral compression ratio, and upper endplate breakage were the independent risk factors for intradiscal cement leakage. Delayed surgery may increase the intradiscal cement leakage through the same mechanism mentioned above. The preoperative vertebral compression ratio and cortical disruption were reported as the risk factors in the prior studies $[18,23,26]$. The vertebral compression reduced the volume of the vertebra resulting in higher pressure as less volume of cement injection. The upper endplate disruption increases the risk of the intradiscal cement leakage was first proposed. It may increase the leakage rate by disrupting the vertebral integrity.

Perivertebral soft tissue cement leakage was asymptomatic. However, it increases the cement injection volume and causes the thermal damage to perivertebral soft tissue. Age, preoperative fracture severity, and preoperative IVC were the independent risk factors of cement perivertebral soft tissue leakage. The preoperative fracture severity and preoperative IVC were reported as risk factors for cement leakage previously [18, 27]. Severe 


Points
Time before surgery
Compression rate
Upper endplate disnuption

Total points

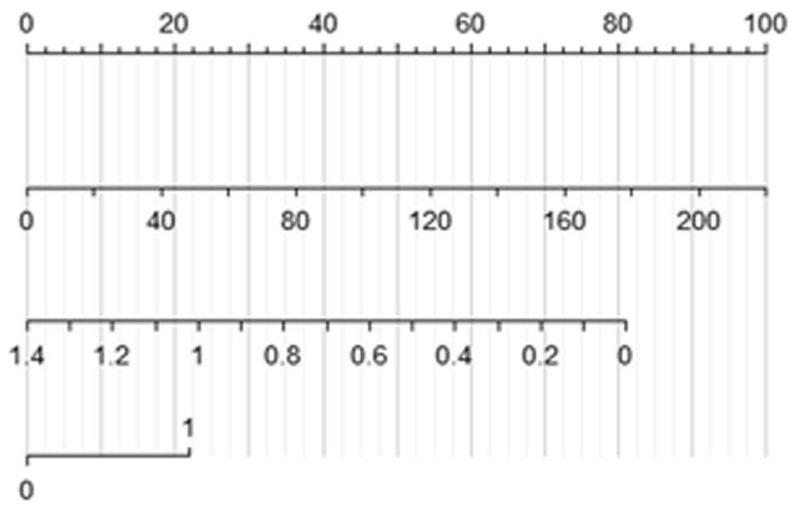

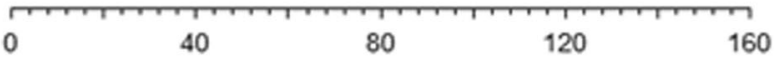

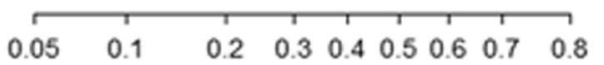

Fig. 3 Nomogram for the intradiscal cement leakage. Mark the values at each factor axis, acquire the corresponding points at the points axis, and sum up the points of all factors. Mark the total points on the total point axis and draw a perpendicular line towards the risk of leakage axis. The value on the bottom line gives the probability of the cement leakage. Upper endplate disruption: yes $=1, \mathrm{no}=0$

fracture and cleft could both produce space for the cement leakage. Age is related to the severity of osteoporosis, and severe osteoporosis leads to the cement leakage. This can explain the age is the risk factor of perivertebral soft tissue cement leakage.

No factor was significantly associated with spinal canal cement leakage. Spinal canal cement leakage seldom leads to neurological injury because the injection would be ceased once the spinal leakage happens under the guidance of $\mathrm{C}$-arm. Therefore, the leakage volume in spinal is always low.

Nomogram is a graphical model in which the probability of the outcome can be calculated. It has been improved to be a feasible model in risk prediction. Zhong [26] provided a nomogram for predicting the intradiscal cement leakage based on postoperative CT. However,

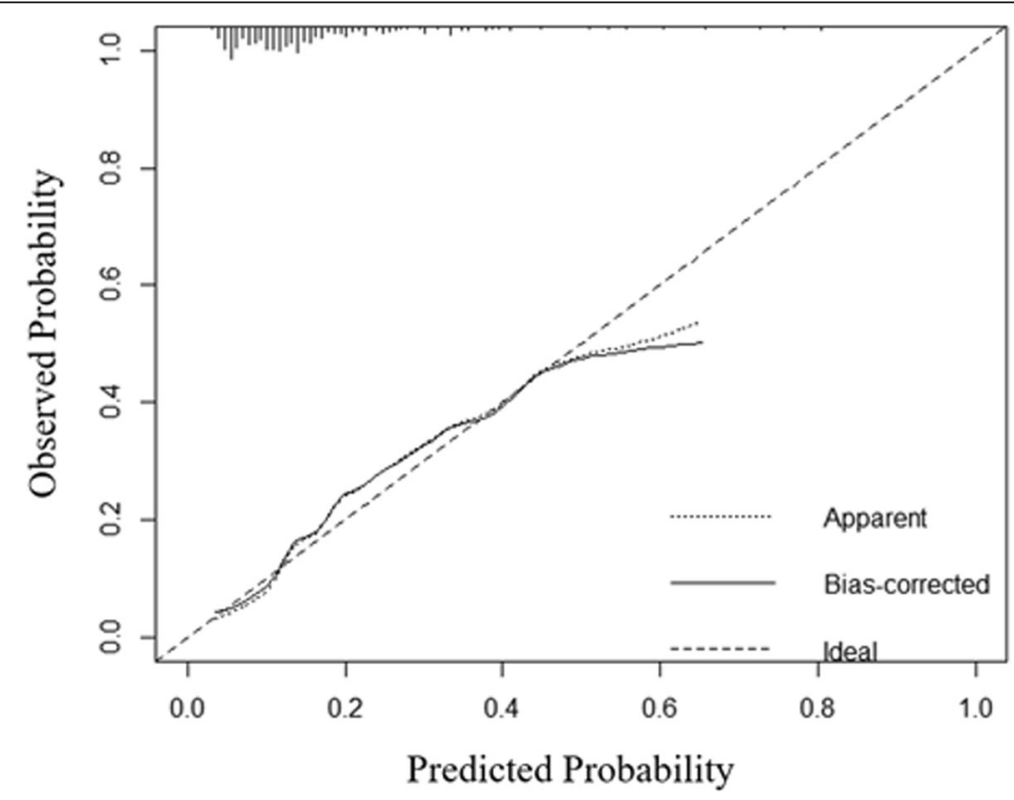

Fig. 4 Calibration of the nomogram. The $x$-axis presents the predicted probability and the $y$-axis presents the observed probability. The concordance index is 0.75 
CT after the vertebral augmentation was not costeffective and practical in most of the hospitals for identifying the cement leakage. X-ray predicting cement leakage is more useful for clinical use. Moreover, the nomogram was not calibrated in his study. Hence, we depicted the nomogram based on a postoperative X-ray and performed a calibration.

Our nomogram could provide a precise prediction ability for the intradiscal cement leakage with a concordance index of 0.75. It is composed of the time before surgery, preoperative vertebral compression ratio, and upper endplate disruption. Therefore, the surgeon can acquire the possibility of intradiscal cement leakage before the surgery and make a well preparation for surgery.

The limitation was that this study was a retrospective research, which could bring the selection bias. We did not calculate the ratio of cement volume with the vertebral volume. The cement volume alone could not predict cement leakage [26]. Finally, the cement viscosity has not been assessed. The cement viscosity was regarded as a risk factor influencing the cement leakage [18, 28]. However, it was difficult to objectively evaluate the cement viscosity because multiple factors could influence it, such as surgeon experience, cement property, and mixing method.

\section{Conclusions}

Delayed surgery and more vertebral compression increase the risk of cement leakage of vertebral augmentation. Different types of cement leakage have different risk factors. We provided a nomogram for precise predicting the intradiscal cement leakage.

\section{Abbreviations \\ OVCFs: Osteoporosis vertebral compression fractures; PVP: Percutaneous vertebroplasty; PKP: Percutaneous kyphoplasty; MRI: Magnetic resonance imaging; IVC: Intravertebral vacuum cleft; VH: Vertebral height; CA: Cobb angle; OR: Odds ratios; Cl: Confidence interval}

\section{Acknowledgments}

Tian-yu Zhang would like to thank Yue Liao for English language editing as well as silent support for life and work.

\section{Authors' contributions}

TYZ and FX conceived the study. TYZ performed data collection, data extraction, statistical analysis, and manuscript drafting. PXZ helped to collect the data and statistical analysis. FX revised of the manuscript. FX, DYZ, and BGJ take responsibility for this study. All authors have read and approved the final manuscript.

\section{Funding}

This study was funded by Beijing Science and Technology Planning Project (D161100002816001); Ministry of Education Key Laboratory of trauma treatment and nerve regeneration (BMU2019XY007-01).

\section{Availability of data and materials}

The datasets generated and analyzed during the current study are not publicly available due to the data also forms part of an ongoing study but are available from the corresponding author on reasonable request.

\section{Ethics approval and consent to participate}

The Ethics Review Committee of Peking University People's Hospital approved this study, with an approval number of 2020PHB 180-01. For this type of study, consent is not required.

Consent for publication

Not applicable.

\section{Competing interests}

Tianyu Zhang, Pei-xun Zhang, Feng Xu, Dianying Zhang, and Baoguo Jiang declare that they have no conflict of interest.

\section{Author details}

'Department of Traumatic Orthopaedics, Peking University People's Hospital, No.11 South Avenue, Xi Zhi Men, Xicheng District, Beijing 100044, China. ${ }^{2}$ Institute of Trauma and Nerve Regeneration, Peking University People's Hospital, Beijing 100044, China. ${ }^{3}$ Department of Orthopaedics, Peking University Binhai Hospital, Tianjin 300450, China.

Received: 29 July 2020 Accepted: 19 November 2020

Published online: 30 November 2020

\section{References}

1. Garfin SR, Buckley RA, Ledlie J. Balloon kyphoplasty for symptomatic vertebral body compression fractures results in rapid, significant, and sustained improvements in back pain, function, and quality of life for elderly patients. Spine. 2006;31(19):2213-20.

2. Ma XL, Xing D, Ma JX, Xu WG, Wang J, Chen Y. Balloon kyphoplasty versus percutaneous vertebroplasty in treating osteoporotic vertebral compression fracture: grading the evidence through a systematic review and metaanalysis. Eur Spine J. 2012;21(9):1844-59.

3. Tomé-Bermejo F, Piñera AR, Duran-Álvarez C, Román BL, Mahillo I, Alvarez L, et al. Identification of risk factors for the occurrence of cement leakage during percutaneous Vertebroplasty for painful osteoporotic or malignant vertebral fracture. Spine. 2014;39(11):E693-e700.

4. Semaan H, Obri T, Bazerbashi M, Paull D, Liu X, Sarrouj M, et al. Clinical outcome and subsequent sequelae of cement extravasation after percutaneous kyphoplasty and vertebroplasty: a comparative review. Acta Radiol. 2018;59(7):861-8.

5. Wang $L$, Yang HL, Shi YX, Jiang WM, Chen L. Pulmonary cement embolism associated with percutaneous vertebroplasty or kyphoplasty: a systematic review. Orthop Surg. 2012;4(3):182-9.

6. Abdul-Jalil Y, Bartels J, Alberti O, Becker R. Delayed presentation of pulmonary polymethylmethacrylate emboli after percutaneous vertebroplasty. Spine. 2007;32(20):E589-93.

7. Kulkarni AG, Shah SP, Deopujari CE. Epidural and intradural cement leakage following percutaneous vertebroplasty: a case report. J Orthopaedic Surg (Hong Kong). 2013;21(3):365-8.

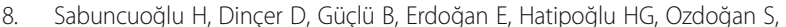
et al. Intradural cement leakage: a rare complication of percutaneous vertebroplasty. Acta Neurochir. 2008;150(8):811-5.

9. Jesse MK, Petersen B, Glueck D, Kriedler S. Effect of the location of endplate cement extravasation on adjacent level fracture in osteoporotic patients undergoing Vertebroplasty and Kyphoplasty. Pain Physician. 2015;18(5): E805-14.

10. Nieuwenhuijse MJ, Putter $H$, van Erkel AR, Dijkstra PD. New vertebra fractures after percutaneous vertebroplasty for painful osteoporotic vertebral compression fractures: a clustered analysis and the relevance of intradiskal cement leakage. Radiology. 2013;266(3):862-70.

11. Rho YJ, Choe WJ, Chun Yl. Risk factors predicting the new symptomatic vertebral compression fractures after percutaneous vertebroplasty or kyphoplasty. Eur Spine J. 2012;21(5):905-11.

12. Yu W, Liang, Yao Z, Qiu T, Ye L, Huang X, et al. Risk factors for recollapse of the augmented vertebrae after percutaneous vertebroplasty for osteoporotic vertebral fractures with intravertebral vacuum cleft. Medicine. 2017;96(2):e5675.

13. Kim YC, Kim YH, Ha KY. Pathomechanism of intravertebral clefts in osteoporotic compression fractures of the spine. Spine J. 2014;14(4):659-66.

14. Yu WB, Jiang XB, Liang $D, X u W X$, Ye LQ, Wang J. Risk factors and score for recollapse of the augmented vertebrae after percutaneous vertebroplasty in 
osteoporotic vertebral compression fractures. Osteoporos Int. 2019;30(2): 423-30.

15. Kim YY, Rhyu KW. Recompression of vertebral body after balloon kyphoplasty for osteoporotic vertebral compression fracture. Eur Spine J. 2010;19(11):1907-12.

16. Venmans A, Klazen CA, van Rooij WJ, de Vries J, Mali WP, Lohle PN. Postprocedural CT for perivertebral cement leakage in percutaneous vertebroplasty is not necessary--results from VERTOS II. Neuroradiology. 2011;53(1):19-22.

17. Zhu SY, Zhong ZM, Wu Q, Chen JT. Risk factors for bone cement leakage in percutaneous vertebroplasty: a retrospective study of four hundred and eighty five patients. Int Orthop. 2016;40(6):1205-10

18. Ding J, Zhang Q, Zhu J, Tao W, Wu Q, Chen L, et al. Risk factors for predicting cement leakage following percutaneous vertebroplasty for osteoporotic vertebral compression fractures. Eur Spine J. 2016;25(11):3411-7.

19. Muijs SP, Nieuwenhuijse MJ, Van Erkel AR, Dijkstra PD. Percutaneous vertebroplasty for the treatment of osteoporotic vertebral compression fractures: evaluation after 36 months. J Bone Joint Surg Brit Vol. 2009;91(3): 379-84.

20. Guan H, Yang H, Mei X, Liu T, Guo J. Early or delayed operation, which is more optimal for kyphoplasty? A retrospective study on cement leakage during kyphoplasty. Injury. 2012;43(10):1698-703.

21. Ren $H$, Shen $Y$, Zhang YZ, Ding WY, Xu JX, Yang DL, et al. Correlative factor analysis on the complications resulting from cement leakage after percutaneous kyphoplasty in the treatment of osteoporotic vertebral compression fracture. J Spinal Disord Tech. 2010;23(7):e9-15.

22. Walter J, Haciyakupoglu E, Waschke A, Kalff R, Ewald C. Cement leakage as a possible complication of balloon kyphoplasty-is there a difference between osteoporotic compression fractures (AO type $\mathrm{A} 1$ ) and incomplete burst fractures (AO type A3.1)? Acta Neurochir. 2012;154(2):313-9.

23. Nieuwenhuijse MJ, Van Erkel AR, Dijkstra PD. Cement leakage in percutaneous vertebroplasty for osteoporotic vertebral compression fractures: identification of risk factors. Spine J. 2011:11(9):839-48.

24. Wang Y, Huang F, Chen L, Ke ZY, Deng ZL. Clinical measurement of intravertebral pressure during vertebroplasty and kyphoplasty. Pain Physician. 2013;16(4):E411-8.

25. Chen WJ, Kao YH, Yang SC, Yu SW, Tu YK, Chung KC. Impact of cement leakage into disks on the development of adjacent vertebral compression fractures. J Spinal Disord Tech. 2010;23(1):35-9.

26. Zhong BY, He SC, Zhu HD, Pan T, Fang W, Chen L, et al. Nomogram for predicting Intradiscal cement leakage following percutaneous Vertebroplasty in patients with osteoporotic related vertebral compression fractures. Pain Physician. 2017;20(4):E513-e20.

27. Tanigawa N, Kariya S, Komemushi A, Tokuda T, Nakatani M, Yagi R, et al. Cement leakage in percutaneous vertebroplasty for osteoporotic compression fractures with or without intravertebral clefts. AJR Am J. Roentgenol. 2009;193(5):W442-5.

28. Anselmetti GC, Zoarski G, Manca A, Masala S, Eminefendic H, Russo F, et al. Percutaneous vertebroplasty and bone cement leakage: clinical experience with a new high-viscosity bone cement and delivery system for vertebral augmentation in benign and malignant compression fractures. Cardiovasc Intervent Radiol. 2008;31(5):937-47.

\section{Publisher's Note}

Springer Nature remains neutral with regard to jurisdictional claims in published maps and institutional affiliations.

Ready to submit your research? Choose BMC and benefit from:

- fast, convenient online submission

- thorough peer review by experienced researchers in your field

- rapid publication on acceptance

- support for research data, including large and complex data types

- gold Open Access which fosters wider collaboration and increased citations

- maximum visibility for your research: over $100 \mathrm{M}$ website views per year

At $\mathrm{BMC}$, research is always in progress.

Learn more biomedcentral.com/submissions 